\title{
OCORRÊNCIA DE INCÊNDIOS FLORESTAIS NO ESTADO DO PARANÁ, NO PERÍODO DE 2005 A 2010
}

\author{
Alexandre França Tetto ${ }^{1}$, Antonio Carlos Batista ${ }^{1}$, Ronaldo Viana Soares ${ }^{1}$ \\ ${ }^{1}$ Eng. Florestal, Dr., Depto. de Ciências Florestais, UFPR, Curitiba, Paraná, Brasil - tetto@ufpr.br; batistaufpr@ufpr.br; \\ rvsoares@ufpr.br
}

Recebido para publicação: 10/08/2011 - Aceito para publicação: 03/04/2012

\begin{abstract}
Resumo
O Paraná possui a terceira maior área de cultivos florestais do país. Uma das preocupações com a cobertura vegetal existente está relacionada com os danos causados pela ocorrência de incêndios florestais. O objetivo deste trabalho foi avaliar o número e época de ocorrência de incêndios, a área atingida e as principais regiões do estado impactadas por esses eventos. Para isso foram analisados os dados do Corpo de Bombeiros do Estado, no período de 2005 a 2010. Os resultados permitiram concluir que nesse período ocorreram 54.793 incêndios, que atingiram 172.130 ha. O período normal de ocorrência de incêndios se concentrou nos meses de junho a setembro, com 52,5\% dos registros. O maior impacto, com relação à vegetação atingida, se deu nos meses de julho a setembro, com 76,0\% da área. A região mais atingida foi a noroeste, com 30,4\% das ocorrências, seguida pela nordeste, com 17,3\%. Em termos de área atingida, o destaque se dá para o noroeste, com 65,6\% da área atingida, seguida pela sudoeste, com 19,0\%. Conclui-se que a região norte foi a mais sujeita à ocorrência de incêndios florestais, em função dos fatores ambientais associados aos incêndios, sobretudo o clima, a tipologia florestal e o uso do fogo em práticas agropecuárias.

Palavras-chave: Área queimada; estação normal de perigo de incêndios; prevenção.
\end{abstract}

\begin{abstract}
Forest fire occurrence in Parana State, in the period 2005 to 2010. Parana holds the third largest area of forest plantations in the country. One of the concerns about the existing vegetation is related to the damages caused by forest fires. This research aimed to determine the fire season, the number of fire occurrences, the burned area, and the main state regions affected by these events. The analyzed data were collected from the State Fire Department, from 2005 to 2010. The results showed that in the analyzed period 54,793 fires, affecting 172,130 ha, were recorded. The main fire season was concentrated in the months of June to September, with $52.5 \%$ of the recorded occurrences. The biggest impact to the vegetation occurred in the months of July to September, with $76.0 \%$ of the affected area. The northwest region was the most affected, with $30.4 \%$ of the occurrences, followed by the northeast, with $17.3 \%$. Regarding the affected area, the northwest region, with $65.6 \%$ of the total, run in first place, followed by the southwest, with $19.0 \%$. The results allowed to conclude that the northern region was more susceptible to the occurrence of forest fires, due to environmental factors associated to the fires, like climate characteristics, vegetation cover, and the use of fire in agricultural practices.
\end{abstract}

Keywords: Affected area; fire season; prevention.

\section{INTRODUÇÃO}

Os maiores e mais destrutivos incêndios florestais registrados no mundo ocorreram sob combinações ideais de material combustível e condições climáticas. A cada ano, apesar da adoção de práticas protecionistas, o fogo destrói ou danifica grandes extensões florestais no mundo (SOARES; BATISTA, 2007). De acordo com os mesmos autores, para o estabelecimento de uma política adequada de prevenção de incêndios, é necessário conhecer as estatísticas referentes aos mesmos. A falta dessas informações pode levar a um dos seguintes extremos: gastos acima do potencial de danos ou gastos pequenos, colocando em risco a sobrevivência da floresta e, sobretudo em eventos extremos, a segurança dos brigadistas. 
A preocupação com os impactos causados pelos incêndios florestais no Brasil teve início após o incêndio que atingiu o estado do Paraná de agosto a setembro de 1963. Esse foi um dos maiores incêndios da história, que atingiu uma área de dois milhões de hectares, cerca de $10 \%$ da superfície do Estado, sendo 20.000 ha de cultivos florestais, 500.000 ha de florestas primárias e 1.480 .000 ha de campo, florestas secundárias e capoeiras. Por ser um assunto novo na época, as ações de combate foram dificultadas, tendo em vista a escassez de pessoal especializado e meios necessários. A partir de então as ações voltadas à prevenção e combate aos incêndios vem sendo aperfeiçoadas, em função da grande probabilidade de ocorrência e do prejuízo que podem causar (SOARES; BATISTA, 1998; PARANÁ, 2002).

Somente em 1983 foi realizado o primeiro levantamento no Brasil sobre ocorrência de incêndios florestais (SOARES; BATISTA, 1998). Analisando os incêndios florestais no Brasil no período de 1983 a 2002, Soares et al. (2006) constataram que o período normal de incêndios engloba os meses de junho a novembro, com um maior número de registros de incêndios no período de agosto a setembro. Trabalho realizado por Avelino (2011), utilizando os dados do Sistema Nacional de Informações sobre Fogo (SISFOGO), concluiu que em 2010 foram registrados 2.270 incêndios florestais no Brasil, atingindo principalmente os estados do Mato Grosso (20,6\%), Pará (14,4\%) e o Ceará (10,9\%). Em termos de unidades de conservação, de acordo com Tetto et al. (2011), foram constatadas 304 ocorrências em 2010, concentradas nos meses de julho a outubro (78\%), atingindo principalmente os estados de Minas Gerais, Piauí e Ceará.

Para Batista et al. (2002), o estado do Paraná apresenta condições favoráveis para a ocorrência de incêndios florestais em determinada época do ano, devido aos fatores climáticos e aos tipos de vegetação existentes. Além disso, uma ocorrência mais intensa de incêndios tem sido observada em anos de invernos mais secos, de forma cíclica, a cada três a cinco anos, de acordo com os dados meteorológicos disponíveis. Pesquisa realizada por Vosgerau et al. (2006), no estado do Paraná, entre 1991 e 2001, identificou 15.890 registros de incêndios, representando uma média anual de 1.444,5 ocorrências. Concluíram que os incêndios florestais no Paraná se concentram no final do inverno e início da primavera, por apresentar as médias mais baixas de precipitação e umidade relativa do ar, época da limpeza e preparo dos solos para plantio agrícola.

Tendo em vista a importância do registro de ocorrência de incêndios e sua análise na prevenção e combate aos incêndios florestais, o objetivo deste trabalho foi avaliar o número e época de ocorrências de incêndios, a área atingida e as principais regiões do estado impactadas por esses eventos.

\section{MATERIAL E MÉTODOS}

\section{Caracterização da área}

O Paraná está situado na região Sul do Brasil, possui uma área aproximada de $199.314 \mathrm{~km}^{2}$, que representa $35 \%$ dessa região. Localiza-se entre as coordenadas geográficas $22^{\circ} 30^{\prime} 58^{\prime \prime}$ e $26^{\circ} 43^{\prime} 00^{\prime \prime}$ de

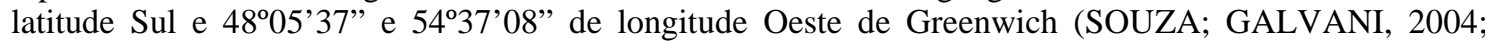
VOSGERAU et al., 2006). O Estado possui clima dos tipos Cfa e $\mathrm{Cfb}$, de acordo com a classificação de Köppen (INSTITUTO AGRONÔMICO DO PARANÁ (IAPAR), 2010). O clima Cfa se caracteriza como temperado, com chuva durante todo o ano e verão quente, com temperatura do mês mais quente acima de $22{ }^{\circ} \mathrm{C}$ e temperatura média do mês mais frio maior ou igual a $-3{ }^{\circ} \mathrm{C}$. O clima $\mathrm{Cfb}$ se caracteriza como temperado, com chuva durante todo o ano e verão morno, com temperatura do mês mais quente abaixo de $22^{\circ} \mathrm{C}$, com pelo menos quatro meses com temperatura maior que $10^{\circ} \mathrm{C}$ e temperatura média do mês mais frio maior ou igual a $-3^{\circ} \mathrm{C}$ (SOARES; BATISTA, 2004).

O estado do Paraná possui a terceira maior área de cultivos florestais do país. Existem 824.648 hectares cultivados com os gêneros Pinus e Eucalyptus, além de aproximadamente 4,4 milhões de hectares de vegetação nativa (SOCIEDADE BRASILEIRA DE SILVICULTURA (SBS), 2008). Para fins de planejamento da Defesa Civil, o Estado está dividido em oito regionais, denominadas Coordenadorias Regionais de Defesa Civil (COREDECs), que formam o elo entre a Coordenadoria Estadual de Defesa Civil (CEDEC) e as Coordenadorias Municipais de Defesa Civil (COMDECs) (DEFESA CIVIL, 2010) (Figura 1).

\section{Ocorrência de incêndios e condições meteorológicas}

O Registro de Ocorrências de Incêndios (ROI) foi obtido e analisado a partir de 2005, ano em que foi implantado o programa SysBM-CCB (COMANDO DO CORPO DE BOMBEIROS (CCB), 2010), que 
informatizou, no estado do Paraná, essas informações. Nesse banco de dados, somente os incêndios atendidos pelo Corpo de Bombeiros são registrados, sendo sua área estimada. Foram consideradas nesse histórico as oito COREDECs, apresentadas no capítulo anterior, para a espacialização dos incêndios.

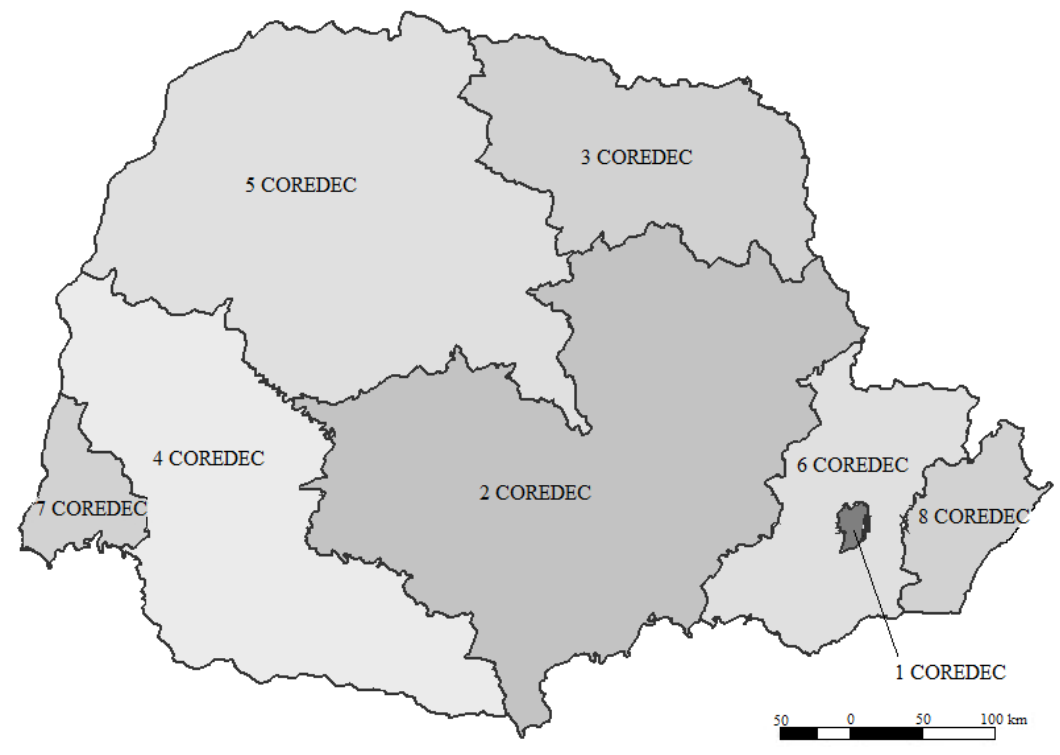

Figura 1. Divisão do Estado em função das COREDECs.

Figure 1. Division of the State in COREDECs.

Fonte: Defesa Civil do Paraná (2011), adaptado pelos autores (2011).

Foram utilizados dados de precipitação pluviométrica do Instituto Agronômico do Paraná (IAPAR), para a verificação da quantidade e distribuição da precipitação nas diferentes COREDECs, bem como o número de dias de chuva por mês. De acordo com metodologia utilizada por Tetto et al. (2010) e Minuzzi et al. (2007), foi considerado como dia chuvoso a precipitação pluviométrica mínima de 1,0 mm. Para a análise da precipitação pluviométrica nas diferentes regiões do Estado, foram selecionadas seis estações meteorológicas como referências. As regionais 1 e 7 , por possuírem áreas relativamente pequenas, foram incorporadas às regionais 6 e 4 , respectivamente.

\section{RESULTADOS E DISCUSSÃO}

\section{Estatísticas dos incêndios}

No ano de 2005, quando foi implantado o sistema de registro e estatística de ocorrências (SysBM-CCB), foram registradas 5.448 ocorrências, que atingiram 12.947,8 ha de vegetação. Em 2006, foram registradas 9.337 ocorrências, com 14.311,9 ha de vegetação atingida. Em 2007, as ocorrências aumentaram para 13.126, com 101.061,2 ha atingidos. Nos anos seguintes, observou-se uma queda no número de ocorrências, 9.435 e 7.198 em 2008 e 2009, respectivamente, enquanto que as áreas atingidas foram de 5.607,4 ha e 6.898,2 ha. Em 2010, o número de ocorrências de incêndios florestais voltou a aumentar, totalizando 10.249 ocorrências e atingindo 31.303,6 ha (Tabelas 1 e 2). Esses resultados corroboram observações feitas por Batista et al. (2002) no que diz respeito à periodicidade de eventos mais intensos a cada três a cinco anos, bem como sua variação ao longo do ano.

Com base na distribuição das ocorrências de incêndios mensais, apresentada na tabela 1, pode-se definir como sendo a estação normal de perigo de incêndios os meses de junho a setembro, com 52,5\% das ocorrências registradas, sendo que o mês de agosto concentrou $17,7 \%$ desses eventos. Em termos de área, o maior impacto na vegetação se deu nos meses de julho a setembro, com $76,0 \%$ da área afetada, apesar de abril se destacar com 9,3\% do total (Tabela 2). 
Tabela 1. Número de incêndios registrados no período analisado.

Table 1. Forest fire occurrence in the analyzed period.

\begin{tabular}{cccccccccccccc}
\hline Ano & Jan & Fev & Mar & Abr & Mai & Jun & Jul & Ago & Set & Out & Nov & Dez & Total \\
\hline 2005 & 88 & 766 & 921 & 429 & 421 & 281 & 389 & 1.166 & 174 & 76 & 275 & 462 & 5.448 \\
2006 & 554 & 254 & 299 & 616 & 1.339 & 979 & 1.131 & 2.041 & 1.118 & 403 & 367 & 236 & 9.337 \\
2007 & 147 & 315 & 761 & 762 & 464 & 2.448 & 1.641 & 2.392 & 2.196 & 1.119 & 428 & 453 & 13.126 \\
2008 & 227 & 474 & 719 & 647 & 837 & 318 & 2.100 & 847 & 1.016 & 395 & 471 & 1.384 & 9.435 \\
2009 & 311 & 253 & 1.035 & 1.896 & 649 & 639 & 183 & 1.020 & 335 & 343 & 305 & 229 & 7.198 \\
2010 & 142 & 488 & 1.033 & 843 & 298 & 854 & 1.072 & 2.227 & 2.205 & 469 & 480 & 138 & 10.249 \\
\hline Total & 1.469 & 2.550 & 4.768 & 5.193 & 4.008 & 5.519 & 6.516 & 9.693 & 7.044 & 2.805 & 2.326 & 2.902 & 54.793 \\
\hline
\end{tabular}

Fonte: CCB (2011), elaborado pelos autores (2011).

Tabela 2. Área afetada (ha) pelos incêndios no período analisado.

Table 2. Affected area during the analyzed period.

\begin{tabular}{|c|c|c|c|c|c|c|c|c|c|c|c|c|}
\hline Ano & Jan & Fev & Mar & Abr & Mai & Jun & Jul & Ago & Set & Out & Nov & Dez \\
\hline 2005 & 20,4 & 168,4 & 494,3 & $9.815,3$ & 73,0 & 45,8 & 85,3 & $1.606,6$ & 56,5 & 85,1 & 105,8 & 391,5 \\
\hline 2006 & 390,7 & 816,6 & 45,9 & 793,3 & $1.097,7$ & 271,3 & $1.030,6$ & $6.364,9$ & $3.130,7$ & 181,6 & 142,0 & 46,6 \\
\hline 2007 & 7,4 & 45,0 & 206,9 & 147,9 & 134,6 & $2.717,7$ & $1.200,6$ & $10.685,9$ & $72.591,0$ & $12.839,7$ & 332,2 & 151,2 \\
\hline 2008 & 39,9 & 114,9 & 191,2 & 269,7 & 197,6 & 106,4 & $1.047,8$ & $1.295,7$ & $1.138,6$ & 276,3 & 253,6 & 675,8 \\
\hline 2009 & 66,0 & 38,6 & 216,2 & $4.719,3$ & 400,1 & 158,5 & 30,1 & 496,9 & 262,6 & 310,1 & 170,7 & 29,0 \\
\hline 2010 & 11,0 & 117,7 & 177,0 & 288,2 & 25,4 & 207,4 & $16.261,1$ & $8.505,7$ & $5.028,0$ & 407,3 & 266,1 & 8,7 \\
\hline Total & 535,4 & $1.301,2$ & $1.331,5$ & $16.033,7$ & $1.928,4$ & $3.507,1$ & $19.655,5$ & $28.955,7$ & $82.207,4$ & $14.100,1$ & $1.270,4$ & $1.302,8$ \\
\hline
\end{tabular}

Fonte: CCB (2011), elaborado pelos autores (2011).

Ocorreram, no período de 2005 a 2010, 54.793 incêndios florestais. Desse total, 30,4\% ocorreram na regional (COREDEC) 5 e 17,3\% na regional 3, ambas situadas na região norte do Estado. Em contrapartida, a regional que menos apresentou ocorrência de incêndios foi a 8, com 1,4\% (Tabela 3).

Tabela 3. Número de ocorrências em função das COREDECs.

Table 3. Number of forest fire occurrences in the state regions.

\begin{tabular}{lcccccccc}
\hline COREDEC & $\mathbf{2 0 0 5}$ & $\mathbf{2 0 0 6}$ & $\mathbf{2 0 0 7}$ & $\mathbf{2 0 0 8}$ & $\mathbf{2 0 0 9}$ & $\mathbf{2 0 1 0}$ & Total & Participação (\%) \\
\hline 1 & 642 & 1.229 & 1.500 & 817 & 711 & 578 & 5.477 & 10,0 \\
2 & 791 & 1.716 & 1.811 & 1.269 & 958 & 1.253 & 7.798 & 14,2 \\
3 & 934 & 1.593 & 2.000 & 1.659 & 1.174 & 2.125 & 9.485 & 17,3 \\
4 & 830 & 1.011 & 1.378 & 1.027 & 991 & 1.406 & 6.643 & 12,1 \\
5 & 1.510 & 2.091 & 4.055 & 3.143 & 2.290 & 3.558 & 16.647 & 30,4 \\
6 & 312 & 1.052 & 1.574 & 906 & 652 & 700 & 5.196 & 9,5 \\
7 & 356 & 495 & 610 & 471 & 342 & 504 & 2.778 & 5,1 \\
8 & 73 & 152 & 197 & 142 & 80 & 125 & 769 & 1,4 \\
\hline Total & 5.448 & 9.339 & 13.125 & 9.434 & 7.198 & 10.249 & 54.793 & 100 \\
\hline
\end{tabular}

Fonte: CCB (2011), elaborado pelos autores (2011).

Na tabela 4, observa-se que o ano que apresentou maior número de ocorrências foi 2007, com $23,9 \%$ do total de ocorrências, seguido pelo ano de 2010 , com $18,7 \%$, e 2008 , com $17,2 \%$. O ano com maior área afetada foi 2007 , com $58,7 \%$, seguida de 2010 , com $18,2 \%$. As regionais mais afetadas foram a 5 e a 4 , com $65,6 \%$ e $19,0 \%$, respectivamente, associadas ao clima da região (Cfa), à unidade fitogeográfica existente (Floresta Estacional) e ao maior uso do fogo em atividades agropecuárias.

\section{Condições meteorológicas}

Com base nos dados meteorológicos do IAPAR, é possível observar uma maior precipitação média anual na estação meteorológica de Morretes, região litorânea, em função de correntes de ar quente e úmido provenientes do Oceano Atlântico e que provocam chuvas orográficas, distribuídas ao longo do ano (Tabelas 5 e 6). Essa estação meteorológica, que representa a regional 8, apresentou a menor 
ocorrência de incêndios e área afetada também em função da sua tipologia florestal (Floresta Ombrófila Densa) que, segundo Myers (2006), possui uma estrutura que tende a inibir o início e propagação do fogo.

Tabela 4. Área afetada (ha) em função das COREDECs.

Table 4. Affected area in the state regions.

\begin{tabular}{|c|c|c|c|c|c|c|c|c|}
\hline COREDEC & 2005 & 2006 & 2007 & 2008 & 2009 & 2010 & Total & Participação (\%) \\
\hline 1 & 30,7 & 106,1 & 113,8 & 58,9 & 55,3 & 22,2 & 387,0 & 0,2 \\
\hline 2 & 482,8 & $2.265,6$ & $3.643,8$ & 757,1 & $1.093,0$ & $1.330,1$ & $9.572,4$ & 5,6 \\
\hline 3 & 274,1 & $3.844,0$ & $2.546,4$ & 688,4 & 811,1 & $1.686,4$ & $9.850,4$ & 5,7 \\
\hline 4 & $1.743,2$ & $3.522,1$ & $17.149,5$ & $1.016,8$ & 473,4 & $8.828,3$ & $32.733,3$ & 19,0 \\
\hline 5 & $10.160,1$ & $3.460,9$ & $73.840,8$ & $2.463,4$ & $4.196,1$ & $18.866,9$ & $112.988,2$ & 65,6 \\
\hline 6 & 116,8 & 916,3 & $3.073,9$ & 384,2 & 201,7 & 317,0 & $5.009,9$ & 2,9 \\
\hline 7 & 138,3 & 176,4 & 683,0 & 232,6 & 66,5 & 241,5 & $1.538,3$ & 0,9 \\
\hline 8 & 1,9 & 20,6 & 10,0 & 6,1 & 1,1 & 11,2 & 50,9 & 0,0 \\
\hline Total & $12.947,8$ & $14.311,9$ & $101.061,2$ & $5.607,4$ & $6.898,1$ & $31.303,6$ & $172.130,0$ & 100 \\
\hline
\end{tabular}

A regional 5 foi a mais suscetível ao fogo, apresentando a menor precipitação média do período. A distribuição da precipitação foi outro fator determinante nas ocorrências dos incêndios. Nessa regional, três meses se destacaram no período analisado: junho, agosto e setembro de 2007, com intensa ocorrência de incêndios (591, 639 e 689, respectivamente) e áreas afetadas (2.112, 1.076 e 66.477 hectares). Esse impacto está diretamente relacionado à série da precipitação pluviométrica que foi, respectivamente, de 9,4,14,7 e 3,2 mm nesses meses. Além disso, conforme relata Vosgerau et al. (2006), essa região possui como prática contínua o uso do fogo para limpeza do solo.

Tabela 5. Precipitação pluviométrica anual $(\mathrm{mm})$ nas estações meteorológicas selecionadas.

Table 5. Annual rainfall in the selected weather stations.

\begin{tabular}{lcccccccc}
\hline Estação meteorológica & COREDEC & $\mathbf{2 0 0 5}$ & $\mathbf{2 0 0 6}$ & $\mathbf{2 0 0 7}$ & $\mathbf{2 0 0 8}$ & $\mathbf{2 0 0 9}$ & $\mathbf{2 0 1 0}$ & Média \\
\hline Guarapuava & 2 & $1.956,1$ & $1.426,8$ & $1.762,6$ & $1.763,5$ & $2.196,3$ & $1.677,1$ & $1.797,1$ \\
Lapa & $6 \mathrm{e} 1$ & $1.767,0$ & $1.268,2$ & $1.420,5$ & $1.629,0$ & $1.816,7$ & $1.862,4$ & $1.627,3$ \\
Londrina & 3 & $1.425,6$ & $1.253,7$ & $1.565,6$ & $1.465,9$ & $2.333,5$ & $1.737,9$ & $1.630,4$ \\
Morretes & 8 & $1.789,8$ & $1.728,4$ & $1.952,9$ & $2.415,6$ & $2.204,0$ & $2.691,4$ & $2.130,4$ \\
Paranavaí & 5 & $1.399,0$ & $1.416,0$ & $1.326,9$ & $1.256,7$ & $2.006,5$ & $1.511,1$ & $1.486,0$ \\
Planalto & $4 \mathrm{e} 7$ & $2.014,4$ & $1.526,5$ & $1.899,0$ & $1.506,4$ & $2.329,2$ & $1.888,9$ & $1.860,7$ \\
\hline
\end{tabular}

Fonte: IAPAR (2011), elaborado pelos autores (2011).

No período de 2005 a 2010, os meses que apresentaram, em média, menor precipitação pluviométrica foram maio, junho e agosto. Destaque deve ser dado à regional 5 (estação meteorológica de Paranavaí), com baixa precipitação de abril a agosto e, consequentemente, maior perigo de incêndios florestais (Tabela 6).

Tabela 6. Precipitação pluviométrica anual média $(\mathrm{mm})$, no período analisado.

Table 6. Average annual rainfall in the analyzed period.

\begin{tabular}{lcccccccccccc}
\hline $\begin{array}{l}\text { Estação } \\
\text { meteorológica }\end{array}$ & Jan & Fev & Mar & Abr & Mai & Jun & Jul & Ago & Set & Out & Nov & Dez \\
\hline Guarapuava & 214,6 & 127,5 & 123,3 & 149,0 & 127,4 & 112,0 & 120,9 & 86,3 & 159,0 & 219,1 & 179,4 & 178,7 \\
Lapa & 191,9 & 141,1 & 135,1 & 129,7 & 84,8 & 77,2 & 114,1 & 78,1 & 174,7 & 192,9 & 131,2 & 176,6 \\
Londrina & 286,4 & 187,9 & 137,0 & 85,1 & 72,2 & 41,2 & 97,8 & 61,3 & 120,6 & 184,8 & 163,0 & 193,1 \\
Morretes & 339,8 & 268,2 & 205,6 & 139,2 & 86,5 & 74,9 & 122,8 & 67,9 & 192,4 & 165,9 & 239,1 & 228,1 \\
Paranavaí & 222,4 & 176,6 & 115,8 & 67,9 & 57,7 & 39,5 & 81,1 & 60,8 & 141,9 & 189,9 & 153,8 & 178,7 \\
Planalto & 188,8 & 123,5 & 101,0 & 181,3 & 191,1 & 98,5 & 100,5 & 104,8 & 134,9 & 288,9 & 154,1 & 193,3 \\
\hline Média & 240,6 & 170,8 & 136,3 & 125,4 & 103,3 & 73,9 & 106,2 & 76,5 & 153,9 & 206,9 & 170,1 & 191,4 \\
\hline Fonte: IAPAR (2011), elaborado pelos autores (2011). & & & & & & & &
\end{tabular}


Observou-se, em média, um menor número de dias de chuva nas estações meteorológicas de Paranavaí (91), Planalto (95) e Londrina (102), que correspondem às regiões de maior ocorrência e área afetada por incêndios no estado do Paraná. Por outro lado, a estação meteorológica de Morretes apresentou 151 dias de chuva em média no período analisado. Nos anos de 2007 e 2010, pode-se observar um menor número de dias de chuva em Paranavaí, Planalto e Londrina, que tiveram como consequência uma maior ocorrência de incêndios (Tabela 7).

Tabela 7. Número de dias de chuva no período de 2005 a 2010.

Table 7. Number of rainy days in the period 2005 to 2010.

\begin{tabular}{lccccccc}
\hline Estação meteorológica & $\mathbf{2 0 0 5}$ & $\mathbf{2 0 0 6}$ & $\mathbf{2 0 0 7}$ & $\mathbf{2 0 0 8}$ & $\mathbf{2 0 0 9}$ & $\mathbf{2 0 1 0}$ & Média \\
\hline Guarapuava & 109 & 98 & 103 & 115 & 130 & 115 & 112 \\
Lapa & 104 & 89 & 95 & 111 & 123 & 123 & 108 \\
Londrina & 98 & 86 & 89 & 108 & 121 & 110 & 102 \\
Morretes & 138 & 139 & 134 & 163 & 169 & 164 & 151 \\
Paranavaí & 93 & 80 & 83 & 84 & 114 & 93 & 91 \\
Planalto & 90 & 86 & 84 & 88 & 115 & 104 & 95 \\
\hline Média & 105 & 96 & 98 & 112 & 129 & 118 & 110 \\
\hline
\end{tabular}

Fonte: IAPAR (2011), elaborado pelos autores (2011).

A tabela 8 apresenta a média mensal do número de dias de chuva, no período de 2005 a 2010. Os meses de maio a agosto foram os que apresentaram menor número de dias de chuva. Esses meses representam, na média, 22,7\% dos dias chuvosos e, praticamente coincidem com a estação normal de perigo de incêndios (junho a setembro, com 52,5\% dos registros de ocorrências).

Tabela 8. Média mensal do número de dias de chuva no período analisado.

Table 8. Monthly average of rainy days during the analyzed period.

\begin{tabular}{lccccccccccccc}
\hline Estação meteorológica & Jan & Fev & Mar & Abr & Mai & Jun & Jul & Ago & Set & Out & Nov & Dez & Total \\
\hline Guarapuava & 14 & 10 & 10 & 8 & 7 & 7 & 7 & 7 & 10 & 13 & 11 & 13 & 116 \\
Lapa & 13 & 10 & 9 & 8 & 7 & 7 & 7 & 7 & 10 & 12 & 8 & 11 & 108 \\
Londrina & 17 & 11 & 9 & 6 & 5 & 5 & 6 & 5 & 7 & 10 & 10 & 11 & 102 \\
Morretes & 20 & 16 & 14 & 12 & 7 & 7 & 8 & 8 & 13 & 16 & 15 & 16 & 151 \\
Paranavai & 15 & 10 & 6 & 6 & 4 & 4 & 5 & 4 & 7 & 10 & 9 & 10 & 91 \\
Planalto & 9 & 8 & 6 & 9 & 7 & 7 & 7 & 6 & 7 & 13 & 7 & 10 & 95 \\
\hline Total & 88 & 65 & 53 & 48 & 38 & 37 & 41 & 35 & 54 & 73 & 60 & 70 & 662 \\
\hline Média & 15 & 11 & 9 & 8 & 6 & 6 & 7 & 6 & 9 & 12 & 10 & 12 & 110 \\
\hline
\end{tabular}

Fonte: IAPAR (2011), elaborado pelos autores (2011).

\section{Ocorrências de incêndios e as condições meteorológicas}

As ocorrências de incêndios florestais estão diretamente relacionadas à quantidade e distribuição da precipitação pluviométrica. Neste trabalho, foi possível observar que existe uma maior correlação entre o número de ocorrências e a precipitação $(\mathrm{r}=-0,77)$ do que entre a área afetada e a precipitação $(\mathrm{r}=-0,14)$ (Figura 2). Isso possivelmente acontece porque a ocorrência dos incêndios florestais está relacionada basicamente à variável fonte de ignição, que tem como agentes causais as atividades antrópicas e os raios, enquanto a área afetada depende dos fatores de propagação do fogo, como topografia, vento, características do material combustível, além de aspectos relativos à eficiência do combate, como tempo de detecção, de mobilização dos brigadistas e de deslocamento, do combate propriamente dito e das operações de rescaldo.

Para o estabelecimento de políticas de prevenção, conforme destacam Soares e Batista (2007), os registros individuais de ocorrências dos incêndios são fundamentais. Esses registros devem conter principalmente informações sobre a época, o local e a causa do incêndio. Durante a análise do registro de ocorrências para esta pesquisa, constatou-se a inexistência da variável "causa do incêndio", por não ser atribuição do Corpo de Bombeiros a sua determinação, conforme estabelece o artigo 45 da Constituição do Estado do Paraná (PARANÁ, 2006). Essa questão foi solucionada pelo Centro Nacional de Prevenção e Combate aos Incêndios Florestais (PREVFOGO), no Sistema Nacional de Informações sobre Fogo 
(SISFOGO), incorporando no registro de ocorrências os campos provável causa e se houve ou não perícia por parte da Polícia Científica (PREVFOGO, 2011).

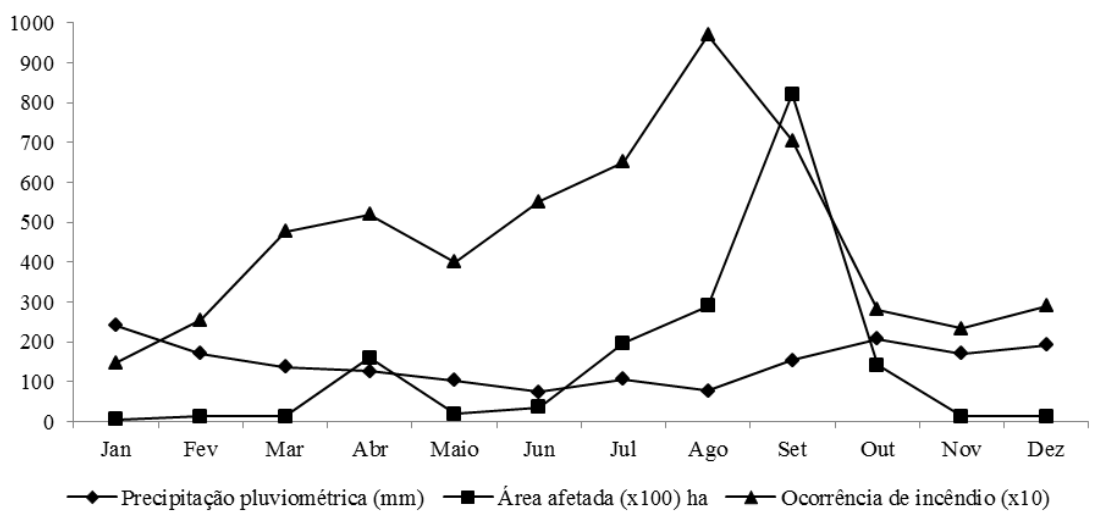

Figura 2. Relação entre os incêndios florestais e a precipitação pluviométrica.

Figure 2. Relationship between rainfall and forest fires.

Fontes: CCB (2011) e IAPAR (2011), elaborado pelos autores (2011).

\section{CONCLUSÕES}

Os resultados permitiram concluir que:

- no período de 2005 a 2010, ocorreram 54.793 incêndios, que atingiram 172.130 ha, concentrados nos meses de junho a setembro (52,5\% dos registros);

- o maior impacto na vegetação ocorreu nos meses de julho a setembro (76,0\% da área), muito embora o mês de abril tenha se destacado (9,3\%);

- a região noroeste foi a mais suscetível para a ocorrência de incêndios florestais, em função de fatores ambientais relacionados aos incêndios, como as características climáticas, a cobertura vegetal e o uso do fogo em práticas agrícolas;

- a região litorânea foi a menos suscetível à ocorrência de incêndios florestais, em função de apresentar a maior precipitação média anual e uma tipologia florestal que tende a inibir o início e a propagação do fogo;

- há uma forte correlação entre o número de ocorrência de incêndios e a precipitação pluviométrica.

\section{REFERÊNCIAS}

AVELINO, A. S. Brigadas do Prevfogo: avaliação dos incêndios florestais de 2010. In: SIMPÓSIO SULAMERICANO SOBRE PREVENÇÃO E COMBATE A INCÊNDIOS FLORESTAIS, 5., 2011, Campinas. Anais... Curitiba, 2011. CD-ROM.

BATISTA, A. C.; OLIVEIRA, D. dos S.; SOARES, R. V. Zoneamento de risco de incêndios florestais para o Estado do Paraná. Curitiba: FUPEF, 2002. 86 p.

CENTRO NACIONAL DE PREVENÇÃO E COMBATE AOS INCÊNDIOS FLORESTAIS (PREVFOGO). Sistema Nacional de Informações sobre Fogo (SISFOGO). Disponível em: <http://siscom.ibama.gov.br/sisfogo/publico.php>. Acesso em: 18/02/2011.

COMANDO DO CORPO DE BOMBEIROS (CCB). SysBM-CCB. Cascavel. Disponível em: <http://www.bombeiroscascavel.com.br/registroccb/>. Acesso em: 14/02/2011.

DEFESA CIVIL DO PARANÁ. Disponível em: < http://www.defesacivil.pr.gov.br/modules/conteudo/ conteudo.php?conteudo=57>. Acesso em: 14/02/2011.

INSTITUTO AGRONÔMICO DO PARANÁ (IAPAR). Disponível em: <http://www.iapar.br/modules/ conteudo/conteudo.php?conteudo=863>. Acesso em: 14/02/2011. 
MINUZZI, R. B.; SEDIYAMA, G. C.; BARBOSA, E. da M.; MELO JÚNIOR, J. C. F. de. Climatologia do comportamento do período chuvoso da região Sudeste do Brasil. Revista Brasileira de Meteorologia, São José dos Campos, v. 22, n. 3, p. 338 - 344, 2007.

MYERS, R. L. Convivendo com o fogo: manutenção dos ecossistemas \& subsistência com o manejo integrado do fogo. Tallahassee: The Nature Conservancy, 2006. 28 p.

PARANÁ. Corpo de Bombeiros. Plano anual de instrução 2002: material de apoio sobre combate a incêndios florestais. Curitiba, 2002. 30 p.

PARANÁ. Constituição do Estado do Paraná 1989. 21 ed. Curitiba: Imprensa Oficial, 2006. 104 p. Disponível em: 〈http://www.imprensaoficial.pr.gov.br/arquivos/File/constituicao.pdf>. Acesso em: 10/01/2011.

SOCIEDADE BRASILEIRA DE SILVICULTURA (SBS). Fatos e números do Brasil florestal. São Paulo: Sociedade Brasileira de Silvicultura, 2008. 92 p.

SOARES, R. V.; BATISTA, A. C. Curso de prevenção e controle de incêndios florestais: o problema do fogo na floresta e meteorologia aplicada aos incêndios florestais: módulo 1. Brasília: ABEAS/UFPR, 1998. 32 p.

Meteorologia e climatologia florestal. Curitiba, 2004. 195 p.

Incêndios florestais: controle, efeitos e uso do fogo. Curitiba, 2007. 264 p.

SOARES, R. V.; BATISTA, A. C.; SANTOS, J. F. Evolution of forest fire statistics in brazilian protected lands in the last 20 years. In: INTERNATIONAL CONFERENCE ON FOREST FIRE RESEARCH, 5, 2006, Portugal. Anais... Portugal, 2006.

SOUZA, I. de A.; GALVANI, E. Diagnóstico da rede de estação meteorológica no estado do Paraná, 1889 a 2003. In: SIMPÓSIO BRASILEIRO DE CLIMATOLOGIA GEOGRÁFICA, 6., 2004. Anais... Aracaju, 2004. $12 \mathrm{p}$.

TETTO, A. F.; BATISTA, A. C.; NUNES, J. R. S.; SOARES, R. V. Subsídios à prevenção e combate a incêndios florestais com base no comportamento da precipitação pluviométrica na Floresta Nacional de Irati, Paraná. Ciência Florestal, Santa Maria, v. 20, n. 1, p. 33 - 43, 2010.

TETTO, A. F.; BATISTA, A. C.; SOARES, R. V. Ocorrência de incêndios florestais em unidades de conservação no Brasil. In: SIMPÓSIO SUL-AMERICANO SOBRE PREVENÇÃO E COMBATE A INCÊNDIOS FLORESTAIS, 5., 2011a, Campinas. Anais... Curitiba, 2011. CD-ROM.

VOSGERAU, J. L.; BATISTA, A. C.; SOARES, R. V.; GRODZKI, L. Avaliação dos registros de incêndios florestais do Estado do Paraná no período de 1991 a 2001. Floresta, Curitiba, v. 36, n. 1, p. 23 32, 2006. 